\title{
Correction: Microglial TIR-domain-containing adapter-inducing interferon- $\beta$ (TRIF) deficiency promotes retinal ganglion cell survival and axon regeneration via nuclear factor-kB
}

Sen Lin ${ }^{1,2}$, Yajie Liang ${ }^{1}$, Jiqiang Zhang ${ }^{1}$, Chen Bian ${ }^{1}$, Hongli Zhou ${ }^{2}$, Qiang Guo ${ }^{1}$, Ying Xiong ${ }^{1}$, Shurong Li Li,3*t $^{*}$ and Bingyin $\mathrm{Su}^{2^{*}+}$

\section{Correction}

After publication of the original article [1] it was brought to the attention of the publishers that several errors were introduced during the typesetting and production process. In the original article Figures six (Figure 1 here), seven (Figure 2 here) and Figure eight (Figure 3) do not correspond to their legends and some typographical errors were introduced into the legends. The publishers regret any inconvenience this may have caused.

It was also noticed by the authors that the image they provided for Figure four panel C (Figure 4 here) was incorrect. The authors apologize for any inconvenience this may have caused.

\footnotetext{
*Correspondence: Isrsu1@yahoo.com.cn; subingyin@yahoo.com.cn

${ }^{\dagger}$ Equal contributors

${ }^{2}$ Department of Histology and Embryology and Neurobiology, Development and Regeneration Key Laboratory of Sichuan Province, Chengdu Medical College, Chengdu 610083, PR China

${ }^{3}$ Department of Pathology, Chengdu Medical College, Chengdu 610083, PR

China

Full list of author information is available at the end of the article
} 


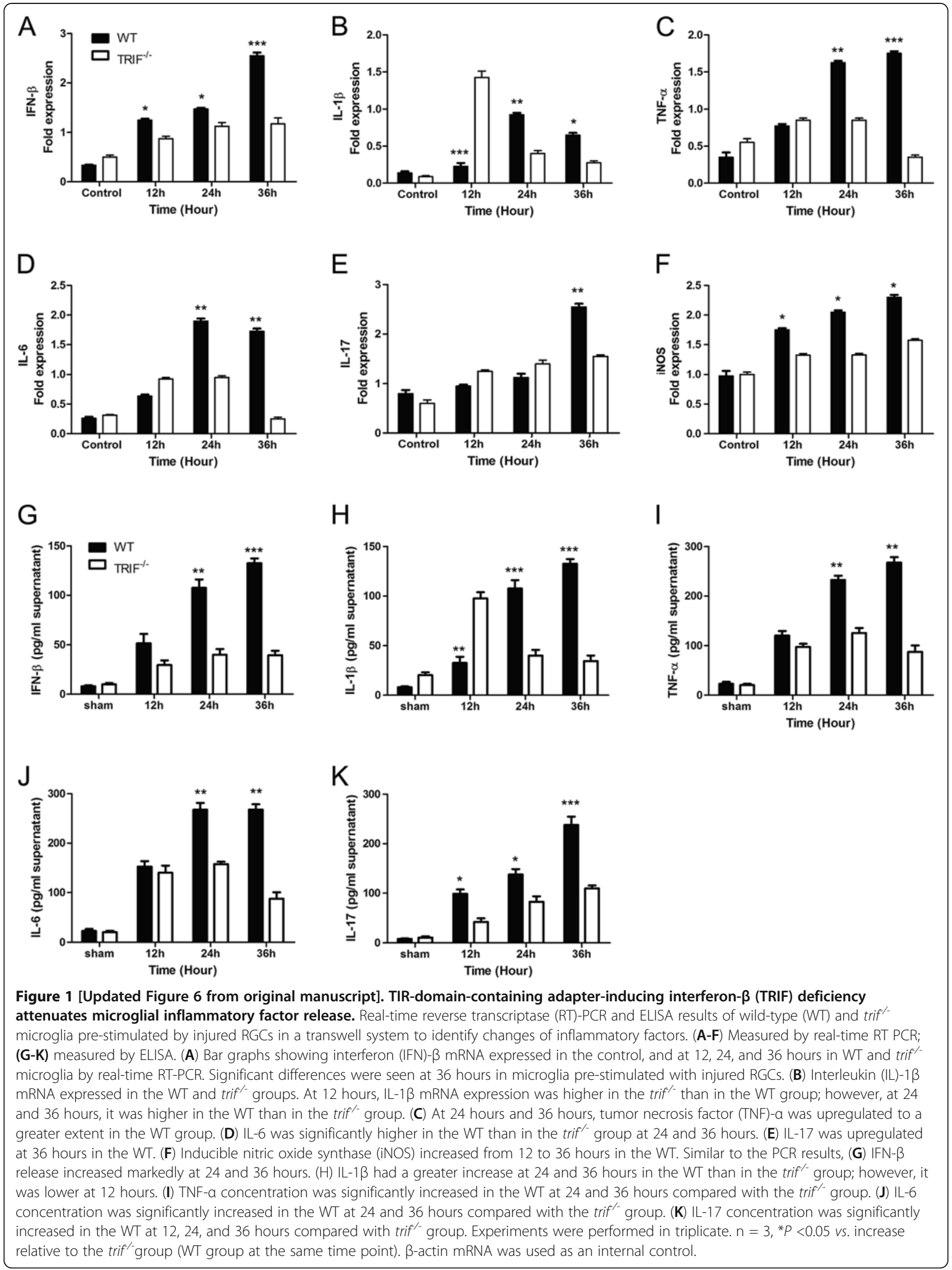




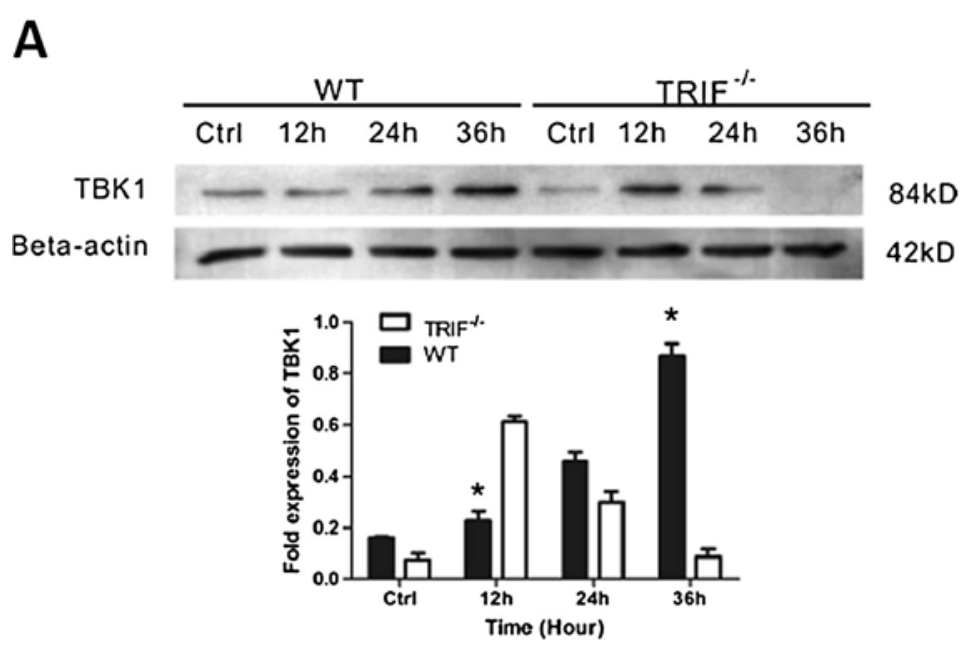

B

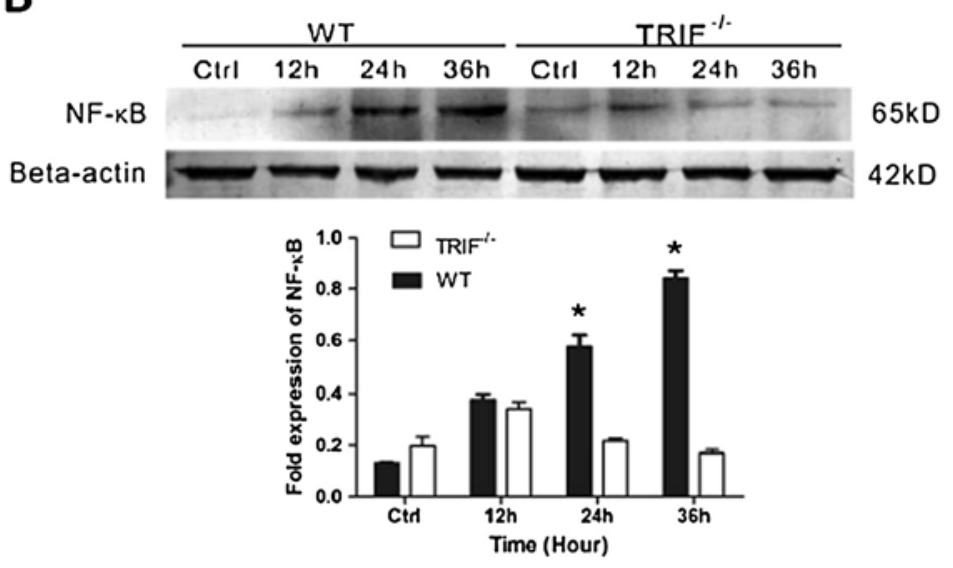

C
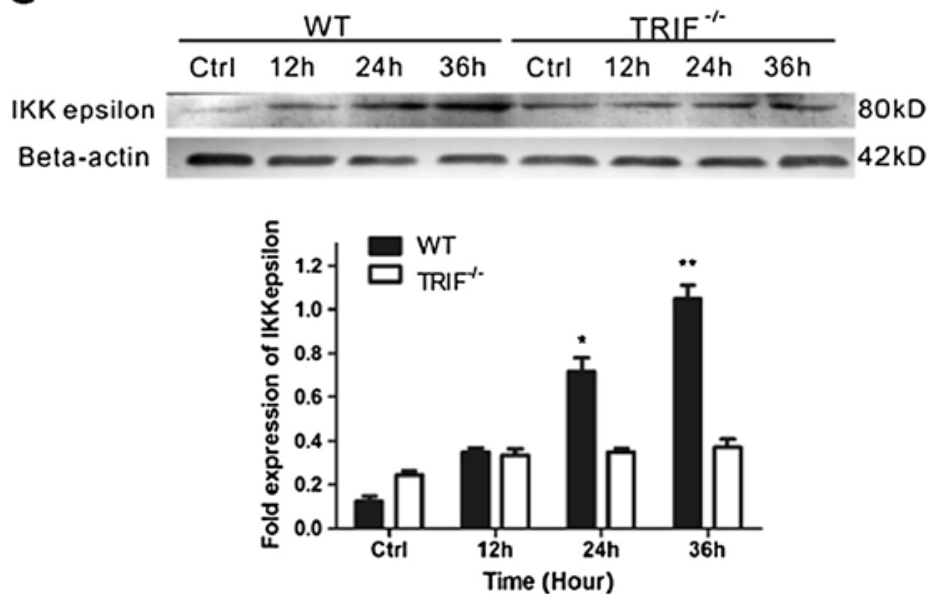

Figure 2 [Updated Figure 7 from original manuscript]. TIR-domain-containing adapter-inducing interferon- $\beta$ (TRIF) deficiency attenuates inflammation via TANK-binding kinase (TBK)1/ ІКB kinase (IKK) $\varepsilon$ and nuclear factor (NF)- KB signaling. Western blot results for wild-type (WT) and trif $^{-1-}$ microglia pre-stimulated by injured retinal ganglion cells (RGCs) in a transwell system identifies the signaling changes downstream of TRIF. (A) Bar graph showing that TBK1 was upregulated gradually in the WT group; however, trif ${ }^{-1-}$ effectively suppressed TBK1 from 24 to 36 hours. (B) Trif ${ }^{-1-}$ effectively suppressed NF-KB from 12 to 36 hours. (C) Bar graph showing that trif ${ }^{-/}$effectively suppressed IKKE from 12 to 36 hours. ${ }^{*} \mathrm{P}<0.05,{ }^{*} \mathrm{P}<0.01$ vs. WT group at the same time point. $\beta$-Actin was used as an internal control. 


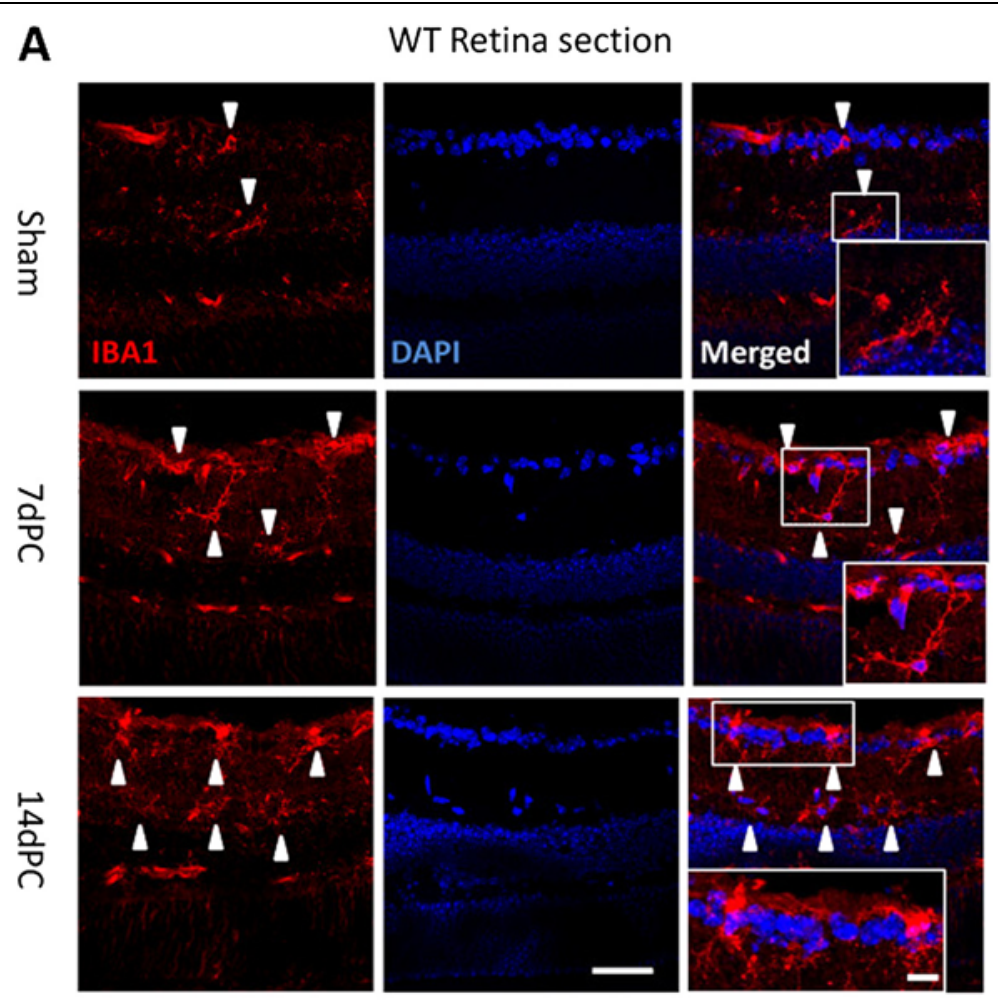

B

TRIF\% Retina section
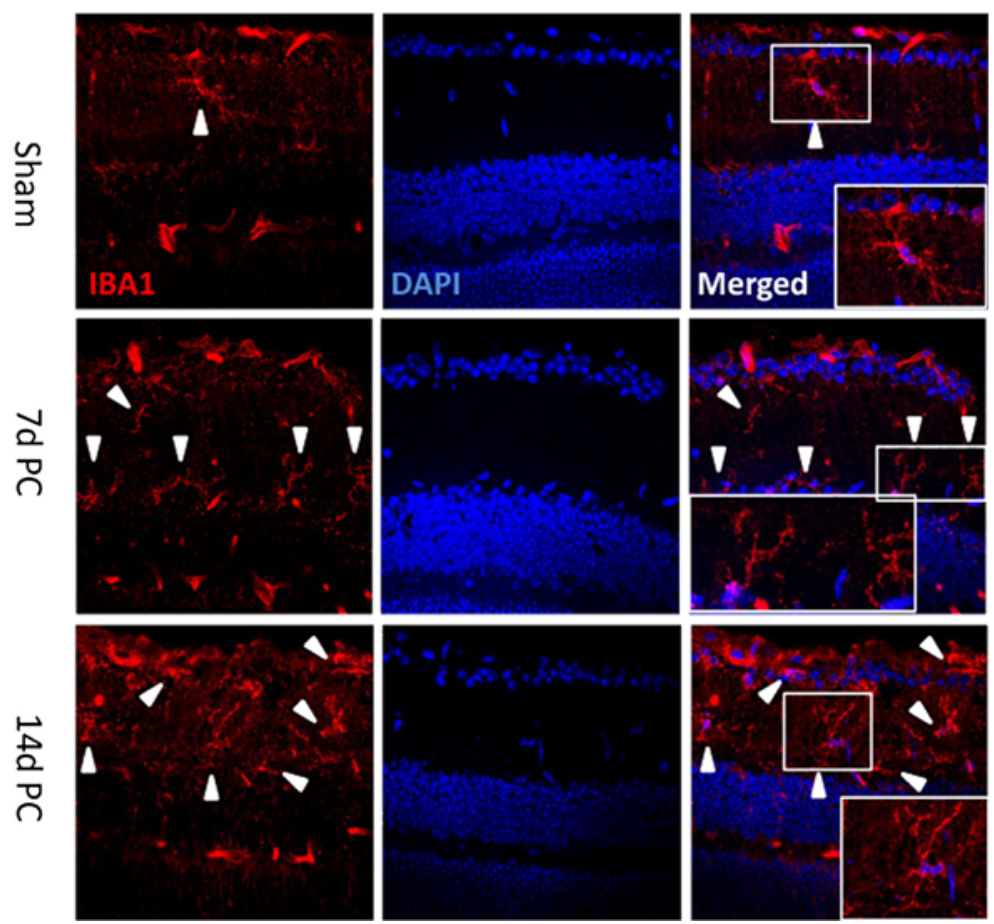

Figure 3 [Updated Figure 8 from original manuscript]. Microglial cells in retinal sections at post-crush days 7 and 14 (7dPC and 14dPC). Microglia in retinal sections were different between the WT and trif $^{-1-}$ groups at $7 \mathrm{dPC}$ and $14 \mathrm{dPC}$. (A) In the WT group, microglia were located in the ganglion cell layer (GCL) and the inner plexiform layer (IPL). After stimulation by ON injury, more microglia were located in the GCL and IPL, and had a ramified and dotted shape at 7dPC. More microglia with a dotted shape and short processes were located in the GCL and IPL at 14dPC. (B) In the trif ${ }^{-1-}$ group, the microglia located in the GCL and IPL had a ramified shape. Scale bar $=20 \mu \mathrm{m}$. Scale bar (in box) $=10 \mu \mathrm{m}$. GCL, ganglion cell layer; IPL, inner plexiform layer. 

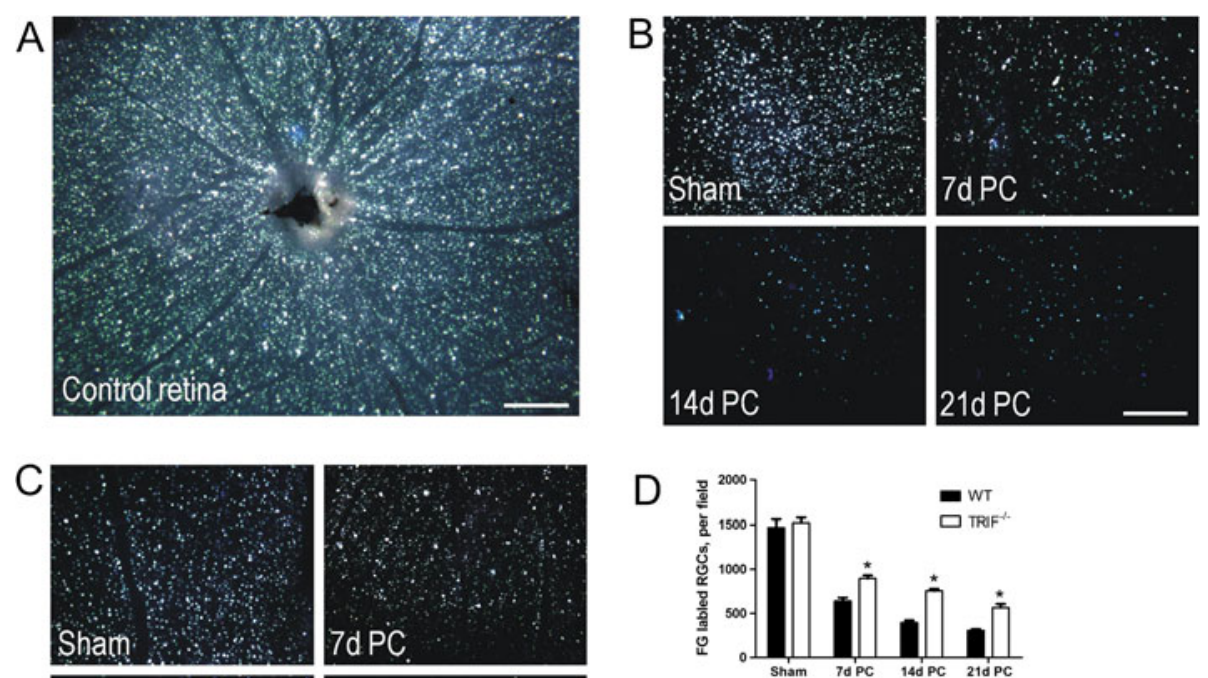

D
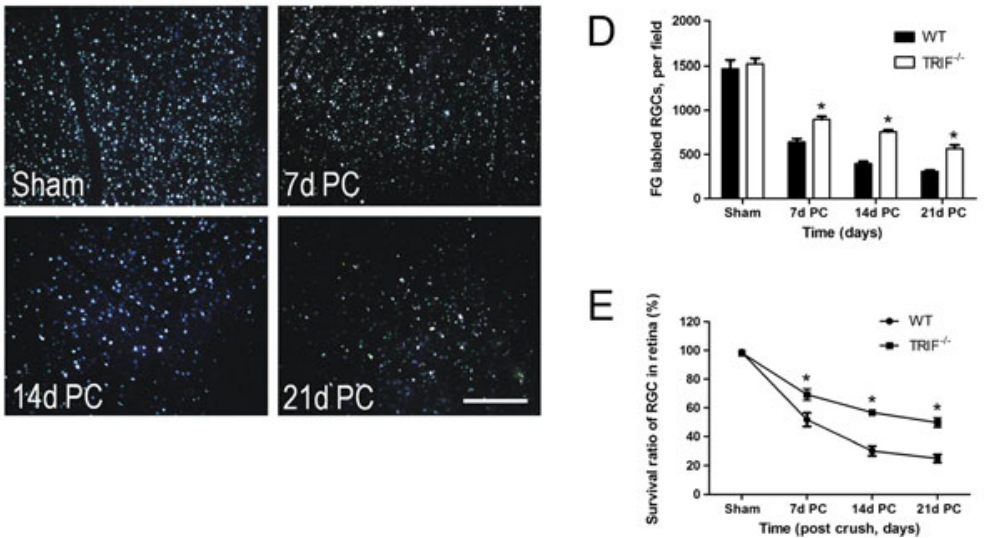

Figure 4 [Updated Figure 4 from original manuscript]. Retinal retinal ganglion cell (RGC) survival detected by Fluorogold (FG) retrograde labeling. (A) FG was transported retrograde to RGC soma in a whole-mount retina used as a control. From 7 to 21 days post-crush (7dPC to $21 \mathrm{dPC}$, FG-labeled RGCs declined in (B) the WT and (C) trif ${ }^{\prime}$ groups. Scale bar, $100 \mu \mathrm{m}$. The number of labeled RGCs was analyzed to confirm that more RGCs survived in the trif ${ }^{\prime-}$ group than in the WT group (D). ${ }^{*} P<0.05$ vs. WT group. (E) Survival ratio of RGCs in trif/- group was higher than that in the WT group from $7 \mathrm{dPC}$ to $21 \mathrm{dPC} .{ }^{*} P<0.05$ vs. WT group.

\section{Author details}

${ }^{1}$ Department of Neurobiology, Chongqing Key Laboratory of Neurobiology, Third Military Medical University, Chongqing 400038, PR China. ${ }^{2}$ Department of Histology and Embryology and Neurobiology, Development and Regeneration Key Laboratory of Sichuan Province, Chengdu Medical College, Chengdu 610083, PR China. ${ }^{3}$ Department of Pathology, Chengdu Medical College, Chengdu 610083, PR China.

Received: 2 April 2013 Accepted: 2 April 2013

Published: 19 April 2013

\section{Reference}

1. Lin S, Liang Y, Zhang J, Bian C, Zhou H, Guo Q, Xiong Y, Li S, Su B: Microglial TIR-domain-containing adapter-inducing interferon- $\beta$ (TRIF) deficiency promotes retinal ganglion cell survival and axon regeneration via nuclear factor-kB. J Neuroinflammation 2012, 9:39.

doi:10.1186/1742-2094-10-48

Cite this article as: Lin et al:: Correction: Microglial TIR-domain-containing adapter-inducing interferon- $\beta$ (TRIF) deficiency promotes retinal ganglion cell survival and axon regeneration via nuclear factor-kB. Journal of Neuroinflammation 2013 10:48.

\section{Submit your next manuscript to BioMed Central and take full advantage of:}

- Convenient online submission

- Thorough peer review

- No space constraints or color figure charges

- Immediate publication on acceptance

- Inclusion in PubMed, CAS, Scopus and Google Scholar

- Research which is freely available for redistribution 